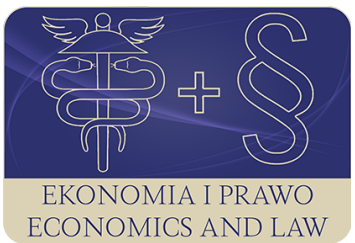

EKONOMIA I PRAWO. ECONOMICS AND LAW

Volume 20, Issue 1, March 2021

p-ISSN 1898-2255, e-ISSN 2392-1625

www.economicsandlaw.pl

ORIGINAL ARTICLE

received 20.05.2020; revised 26.03.2021; accepted 31.03.2021

Citation: Ganescu, M.C., \& Serbanica, C.M. (2021). Regional innovation performance and structural conditions in Central and Eastern Europe: embracing the broad-based innovation concept. Ekonomia i Prawo. Economics and Law, 20(1): 107-119. doi:10.12775/EiP.2021.007.

\title{
Regional innovation performance and structural conditions in Central and Eastern Europe: embracing the broad-based innovation concept
}

\author{
MARIANA CRISTINA GANESCU \\ corresponding author \\ “Constantin Brancoveanu” University of Pitesti, Faculty of Finance-Accounting, \\ Calea Bascovului Street 2A, 110095, Pitesti, Romania \\ $\square$ cristina_ganescu@yahoo.com \\ (D) orcid.org/0000-0001-8610-3542

\section{CRISTINA MARIA SERBANICA} \\ "Constantin Brancoveanu” University of Pitesti, Faculty of Juridical, Administrative \\ and Communication Studies, Romania \\ 曰 cpantelica@yahoo.co.uk \\ (D) orcid.org/0000-0001-9676-351X
}

\begin{abstract}
Motivation: There is plenty of evidence suggesting that the (regional) innovation systems in Central and Eastern Europe (CEE) are in their early beginnings and that this poses huge challenges to the implementation of the smart specialization agendas and to the efficient use of the European structural and investment funds in these countries. Our assumption is that structural differences explain to a large extent the differences in innovation performance between the CEE and non-CEE regions and that the future growth trajectories of the CEE regions should more specifically embrace the broad-based innovation concept.

Aim: Our study attempts to test whether there are statistically significant differences between the CEE and non-CEE regions in each component of the European Regional Innovation Scoreboard and whether such differences can be explained by the variations in structural conditions. To this purpose, we use a discriminant factor analysis and test the correlations between the discriminant function and various structural indicators.
\end{abstract}


Results: The R\&D-based component of the regional innovation systems discriminates the most between the CEE and the non-CEE regions. In contrast, the differences between the two groups are minimal in terms of Non-R\&D innovation expenditure, Tertiary education or Employment in Medium and High-Tech Manufacturing. On the whole, the differences in innovation performance, as reflected by the discriminant function, can be largely attributed to the differences in economic performance (GDP per capita) and in the industrial structures. All these considerations give support for the adoption of the broad-based innovation policy at the CEE level, which goes beyond the R\&D investments and gives widespread support to both technological and non-technological innovation, skills upgrading or the integration into international networks and value chains.

Keywords: regional innovation performance; broad-based innovation; structural conditions; Central and Eastern European regions JEL: O32; R58; O52

\section{Introduction}

30 years after the collapse of the communist bloc, Central and Eastern European countries that have joined the European Union have definitely begun to embark on innovation-based growth trajectories. The EU Cohesion Policy plays an important role in the uptake of innovation at the CEE level, as significant funding has been allocated to these regions to catch-up with the more developed regions. Yet, there is plenty of evidence suggesting that the regional innovation systems in these countries are in their early beginnings and this poses huge challenges to the implementation of the smart specialization agendas and to the effective use of the European structural and investment funds.

On these assumptions, our paper aims to provide evidence on the characteristics of the regional innovation systems and the drivers of regional innovation performance in Central and Eastern Europe (CEE). The group includes 11 countries that were previously part of the communist bloc and joined the European Union after 2004, namely Bulgaria, the Czech Republic, Croatia, Estonia, Lithuania, Latvia, Hungary, Poland, Romania, Slovakia and Slovenia. In particular, we are interested in finding out which are the innovation indicators that discriminate the most between the CEE regions and the other (non-CEE) EU regions and to emphasize the implications for innovation policy making.

The reminder of the paper is organized as follow: Section 2 contextualizes the research by providing background information on the state of RIS development in Central and Eastern Europe. Section 3 gives an overview of the research method and the data sources used in the analysis. Section 4 summarizes the results of our work. The conclusions are reported in Section 5.

\section{Literature review}

The interest of researchers and policy makers on regional innovation systems (RIS) has largely increased in recent decades, "partly by the growing interest 
in innovation as a source of competitive advantage, and partly by the need for new policies to address regional inequalities and divergence" (Asheim et al., 2011, p. 875). According to Asheim \& Gertler (2005), an innovation system consists of the production structure (techno-economic structures) and the institutional infrastructure supporting innovation (political-institutional structures). The innovation system concept can be understood in both a narrow, as well a broad sense (Asheim et al., 2019). In a narrow sense, the innovation system incorporates the R\&D functions of universities, public and private research institutes and corporations. In a broader sense, the innovation system includes "all parts and aspects of the economic structure and the institutional set-up affecting learning as well as searching and exploring" (Lundvall, 1992, p. 12). In a simplified form, the regional innovation system is a cumulative and non-linear systemic process that "results from the formal and informal, voluntary and involuntary interactions between different agents operating in the innovative system" (OECD, 2011, p. 38).

Asheim et al. (2019, p. 2) have recently produced a comprehensive summary of the evolution of the concept of regional innovation systems and have explained their role in increasing the regional innovation capacity. In particular, the authors demonstrate how the economic and institutional context influences the innovation capacity of the regions, while shedding light on three main constituents of a RIS: the actors, networks and institutions. The actors are the firms and industries, located in a particular region, plus the universities, research bodies, knowledge transfer, policy actors, non-governmental organisations and other innovation actors. The networks facilitate the exchange of knowledge between the RIS actors, while the institutions create a framework of formal and informal norms or set "the rules of the game" in regional innovation systems.

The lagging-behind regions or the regions with less developed regional innovation systems were deemed a special attention in the RIS literature. As pointed out by Asheim et al. (2015, p. 7), "in developing countries, the regional innovation systems are characterised by a low level of capabilities of indigenous firms, labour, but also knowledge generating organisations such as universities and research organisations". In the same vein, the OECD (2011, p. 43) categorization of regions based on their innovation potential reveals that most regions in Central and Eastern European countries may be classified as "non science and technology-driven regions"; on few exceptions (i.e. the capital regions), most regions in this part of Europe fall into the category of "structural inertia or de-industrializing regions" or "primary-sector-intensive regions" and are characterized by persistent underdevelopment traps, considerably lower GDP per capita as compared to the other groups and the lowest values for patenting and other research and development indicators. Our previous investigation of the regional innovation typologies in Central and Eastern Europe has led to similar conclusions: the CEE region hosts few advanced and intermediate regions (i.e., Estonia, Prague, Lijubiana, Budapest, Warsaw, Bucharest etc.), 
while most of the remaining regions are "lagging-behind", both in terms of innovation performance and productivity (Serbanica et al., 2018).

Radosevic (2002) draws our attention to the fact important elements of the RIS are missing from Central and Eastern Europe, such as capable organisations in both the knowledge generation and knowledge exploitation subsystems, the networks and knowledge linkages between the regional innovation actors or the institutions that support innovation. In his opinion, the region should move beyond the traditional innovation policies that are too focused on research and development to policies geared towards other sources of productivity growth (non-R\&D areas), such as the upgrading of their technologies, management practices, skills, quality and engineering. Such efforts could help the enterprises improve their capabilities and the value-added positions in international value chains (Radosevic, 2017).

Different other authors point to the various deficiencies of the RIS systems in Central and Eastern Europe and to the need to adopt tailor-made policies and make more efficient use of Cohesion policy and smart specialisation resources. Gorzelak (2019, p. 1-2) observes that in spite of unquestionable success in economic growth and institutional reforms, the CEE countries have not succeeded to overcome some critical weaknesses in the post-transition period; of these, the dependence on foreign direct investments and the poor endogenous innovation potential for innovation are considered the main weaknesses of Central and Eastern Europe, which may stick the region to the "middle income trap". Havas (2015) notes the persistence of the science-push models of innovation and of the "high-tech myths" in Central and Eastern Europe and suggests that innovation policy in the region should be orchestrated across several policy domains and several sectors (including low-tech and medium-tech sectors). Using data on regional public spending, industrial structure and economic performance, Muscio et al. (2015) also confirm the persistence of the regional innovation paradox in Central and Eastern Europe, where higher R\&D investments do not necessary translate into higher returns in terms of scientific excellence and economic performance. The main explanation to this paradox is that the CEE regions are "structurally weak" regions that need deep structural economic transformations to be able to transform the R\&D outputs into valuable socio-economic outcomes.

Based on these findings, our study aims to compare the innovation performance of the CEE and non-CEE regions in both the R\&D and non-R\&D components and to test whether the differences can be explained by the variations in structural conditions. Our assumption is that such conclusions could better inform the smart specialization agenda at the CEE level on how to maximize the returns from public investments in priority areas. 


\section{Methods}

To our purpose, we use the European Regional Innovation Scoreboard 2019 database (European Commission, 2019) and carry out a discriminant function analysis (DFA); in a further step, we test the correlations between the discriminant function and different structural indicators (GDP per capita, sectoral employment, demographics). In this respect, we use SPSS programme (Bian, n.d.; Landau \& Everitt, 2003; Leech et al., 2005).

The European Regional Innovation Scoreboard 2019 covers 238 regions at different NUTS levels from the EU Member States, Norway, Serbia and Switzerland. In our analysis, we have only considered the EU regions (57 CEE regions and 163 Non-CEE regions). The database does not include the normalized scores for Cyprus, Estonia, Latvia, Luxembourg and Malta, so these countries were not included in the analysis.

The discriminant function analysis is a statistical procedure that works with data already classified into groups (a categorical dependent variable) and several continuous independent variables. The DFA calculates a discriminant function based on a weighted combination of the independent variables that provide the best discrimination between the predefined groups. In our study, the dependent variable has two categories (Group 0=CEE regions and Group l=Non$\mathrm{CEE}$ regions) and the independent variables are the innovation indicators included in the European Regional Innovation Scoreboard (Table 1).

DFA works under the assumption of linearity, the multivariate normal distribution of predictor variables and the homogeneity of variance-covariance matrices across the groups (Leech et al., 2005). In our case, the innovation indicators included in the European Regional Innovation Scoreboard and considered in our study are normalized by means of square root transformation and min-max procedures. The assumption of homogeneity of the covariance matrices is not fully met, as confirmed by the Box's M test $(F(3.580)=357.982$; Sig. .000); yet, there is evidence that that discriminant function analysis is robust even when the homogeneity of variances is not met, on condition that the data do not contain large outliers (Landau \& Everitt, 2003; Leech et al., 2005), which is valid for our case. The independent variables are entered in the analysis in a stepwise manner and the prior probabilities are computed on the observed group sizes, given that the two groups are unequal in size.

\section{Results}

The resulting descriptive output is shown in Table 1, where the means and standard deviations of each of the independent variables are presented. One can easily observe that the mean scores of the CEE regions are lower than of the Non-CEE regions, but the differences for some indicators are particularly low (for example, for Non-R\&D innovation expenditures etc.). 
Since the dependent has two categories, there is only one discriminant function resulted from the analysis (Table 2). This function is statistically significant (Wilk's Lambda=.161; p<.001) (Table 3), which indicate that the model is suitable to differentiate between the two groups and explain the variance in the dependent variable (canonical correlation $=.916$ ).

The Structure Matrix (Table 4) represents the correlations between each independent variable and the standardized discriminant function, ordered by absolute size. 13 out of the initial 17 RIS Indicators are retained in the model.

As it results from the Table 4, the variable that discriminates the most between the CEE and Non-CEE regions is the "Most-cited publications", which is an indicator of the attractiveness of the research systems and has important connections with the scientific productivity measured in the number of international publications, number of public-private co-publications and patents applied at the international level. In a decreasing order, the number of SMEs introducing product, process, marketing and organisational innovations differs considerably between the CEE and the Non-CEE regions and has chain-effects over the sales of new-to-market and new-to-firm innovations. In contrast, the differences between the two groups are minimal in terms of "Non-R\&D innovation expenditure", "Tertiary education", "Employment in medium and high tech manufacturing and knowledge-intensive services, "Designs applications" or "Trademark applications".

Four indicators ("SMEs Innovating in-house", "International scientific co-publications", "Trademark applications" and "Tertiary Education") are not entered in the discriminant function due to their low tolerances (multicollinearity) and/or low F level. The "SMEs Innovating in-house" indicator has a very large correlation $(r=.975)$ with "Product or process innovators", while the "International scientific co-publications" indicator is highly correlated $(\mathrm{r}=.806)$ with "R\&D expenditure public sector"; on the other hand, the number of "Trademark applications" and the participation in "Tertiary education" have medium-to-low correlations with all the other innovation indicators, which means that their distribution across regions is highly heterogeneous.

The centroids (Table 5) are the mean discriminant scores for each group and serve as the cutting points for classifying the cases according to the discriminant function. Based on these centroids, the Classification Results (Table 6) show that $97.7 \%$ of original cases can be correctly classified using the discriminant function, whose predictive power is thus very high.

Table 7 represents the correlations between the discriminant function and different structural indicators that are supposed to influence the innovation performance. From Table 7, it can be concluded that the differences in innovation performance - as reflected in the discriminant function - can be largely attributed to differences in GDP per capita $(r=.705)$ and in the economic structure, especially in employment in services $(r=.617)$, whose share in total employment is much lower at the CEE level (Table 1). On the contrary, employment in agriculture and employment in industry have negative correlations with 
the discriminant function, while population density does not seem to have a very strong impact on innovation performance.

Finally, Chart 1 displays graphically the relationship between the GDP per capita and the Regional Innovation Index composite indicator (European Commission, 2019), so that to make the correlation more prominent. One can easily observe from Chart 1 that except for the regions that host the capital cities (CZ0 - Prague, SI04 - Lijubliana, SK01 - Bratislava, PL91 - Warsaw, HUll - Budapest, LT01 - Vilnius), which are better placed to progress towards the knowledge frontier, all the other CEE regions stay at the bottom of both GDP per capita and innovation-based ranking.

\section{Conclusions}

Our study has identified those innovation indicators that discriminate the most between the CEE and the Non-CEE regions and has tested the influence of structural conditions on innovation performance. Some important conclusions can be derived from this analysis.

First, the CEE regions are still lagging behind in innovation performance when compared to the regions in Western Europe and the differences between the two groups can be largely attributed to the variations in the R\&D-based component of the innovation systems (international scientific publications, most-cited publications, PCT patent applications etc). The conclusion that can be drawn from this finding is that the CEE countries are still far from being $R \& D$-based economies, as they have important deficits in terms of R\&D personnel and R\&D expenditures (especially in the public sector), which impacts strongly on the attractiveness and quality of the research systems.

A second group of variables with large discriminatory power are those that refer to the number of SMSs introducing product, process, marketing and organisational innovations or innovating in-house. Such a weakness may be attributed partly to the low innovation culture that still exist in the CEE countries that were part of the communist block for a long period in the last century and lacked the market economy experience.

Third, the differences in the economic structure and economic performance structure do also matter for this divide, as long as GDP per capita and employment in services are very strong predictors for innovation performance. The sole CEE regions departing from the group in terms of innovation performance are the capital regions and few metropolitan areas where the service sector is more prominent and the GDP per capita - which is a proxy for the demand of innovation - is probably twice or higher than the national average.

In contrast, the differences between the two groups are minimal in terms of Tertiary education, Employment in medium and high-tech manufacturing and knowledge-intensive services, Non-R\&D innovation expenditure or the Applications for designs (and even Trademarks). Even if some important 
within-group differences exist with respect to these variables, we think that they should be further seen as main drivers of growth at the CEE level.

All these considerations make strong arguments for the adoption of the broadbased innovation policy at the CEE level, which gives large support to learning and skills, diffusion of new technologies, investments in all forms of innovation (R\&D-based, technological and non-technological, social innovation, service innovation etc.) and integration into international networks and value chains. In order to progress to the knowledge frontier, the CEE regions are expected to better valorise their skills base, especially the tertiary educated population, while investing in the lifelong learning component, which is currently very low at the CEE level.

Moreover, as our study confirmed, the CEE regions are taking ambitious steps forward in adopting the new technologies and making investments in equipment, machinery and know-how (non-R\&D innovation); such an endeavour could reduce the technological gap with the most advanced regions and better prepare the CEE regions for the knowledge-based society. At the same time, one should acknowledge the fact that the CEE regions have a good record for employment in medium and high=tech manufacturing and knowledge-intensive services, which may be partly attributed to the presence of foreign direct investments. Taking better advantage of the relocation of Western industries in the CEE region and embedding the multinational companies in the regional innovation systems could open new routes to access the international networks and global value chains. All these findings are consistent with the smart specialization logic, whose main goal is to support a broad technology-driven economic transformation.

\section{References}

Asheim, B.T., \& Gertler, M.S. (2005). The geography of innovation: regional innovation systems. In J. Fagerberg, D.C. Mowery, \& R. Nelson (Eds.), The Oxford handbook of innovation. Oxford: Oxford University Press. doi:10.1093/oxfordhb/9780199286805.003.0011.

Asheim, B.T., Grillitsch, M., \& Trippl, M. (2015). Regional innovation systems: past, presence, future. Papers in Innovation Studies, 36.

Asheim, B.T., Isaksen, A., \& Trippl, M. (2019). Advanced introduction to regional innovation systems. Northampton: Edward Elgar.

Asheim, B.T., Lawton Smith, H., \& Oughton, C. (2011). Regional innovation systems: theory, empirics and policy. Regional Studies, 45(7). doi:10.1080/0 0343404.2011 .596701$.

Bian, H. (n.d.). SPSS discriminant function analysis. Retrieved 02.02.2020 from http://core.ecu.edu.

European Commission. (2019). Regional innovation scoreboard 2019: methodology report. Retrieved 02.02.2020 from https://ec.europa.eu.

Eurostat. (2020). Database. Retrieved 02.02.2020 from https://ec.europa.eu. 
Gorzelak, G. (Ed.). (2019). Social and economic development in central and eastern Europe: stability and change after 1990. London: Routledge.

Havas, A. (2015). The persistent high-tech myth and its implications for the EU10 countries. GRINCOH Working Paper Series, 3.14. doi:10.2139/ ssrn.2572952.

Landau, S., \& Everitt, B. (2003). A handbook of statistical analyses using SPSS. New York: Chapman \& Hall.

Leech, N.L., Barrett, K.C., \& Morgan, G.A. (2005). SPSS for intermediate statistics: use and interpretation. Mahwaj: Lawrence Erlbaum.

Lundvall, B.A. (Ed.). (1992). National systems of innovation: towards a theory of innovation and interactive learning. London: Pinter.

Muscio, A., Reid, A., \& Leon, L.R. (2015). An empirical test of the regional innovation paradox: can smart specialisation overcome the paradox in Central and Eastern Europe. Journal of Economic Policy Reform, 18(2). doi:10.1080/17 487870.2015 .1013545$.

OECD. (2011). OECD reviews of regional innovation: regions and innovation policy. doi:10.1787/9789264097803-en.

Radosevic, S. (2002). Regional innovation systems in central and eastern Europe: determinants, organizers and alignments. The Journal of Technology Transfer, 27(1). doi:10.1023/A:1013152721632.

Radosevic, S. (2017) . Upgrading technology in Central and Eastern European economies. IZA World of Labor, 338. doi:10.15185/izawol.338.

Serbanica, C., Ene, S., Ganescu, C., \& Talmaciu, I. (2018). Regional innovation typologies in Central and Eastern Europe: the path to regional transformation. Contemporary Economy, 3(4).

\section{Acknowledgements}

Author contributions: authors have given an approval to the final version of the article. Authors contributed to this work equally.

Funding: this research was undertaken as part of the Smart specialization in lagging behind regions in Central and Eastern Europe (PN-III-Pl-1.1-TE-2016-1630) project and was fully funded by a grant of Ministry of Research and Innovation (CNCS-UEFISCDI, PNCDI III). 


\section{Appendix}

Table 1.

\section{Group Statistics}

\begin{tabular}{|c|c|c|c|c|c|}
\hline \multirow{2}{*}{$\begin{array}{l}\text { A. Innovation Indicators } \\
\text { Definitions }\end{array}$} & \multirow[b]{2}{*}{ Name } & \multicolumn{2}{|c|}{$\begin{array}{l}\text { CEE regions } \\
\qquad \mathrm{N}=57\end{array}$} & \multicolumn{2}{|c|}{$\begin{array}{l}\text { Non-CEE regions } \\
\quad \mathrm{N}=163\end{array}$} \\
\hline & & Mean & STD & Mean & STD \\
\hline $\begin{array}{l}\text { Tertiary Education: Population having completed tertiary } \\
\text { education (\%) }\end{array}$ & TertEdu & .3884 & .2289 & .4285 & 1759 \\
\hline $\begin{array}{l}\text { Lifelong learning: Population participating in lifelong learning } \\
\text { (\%) }\end{array}$ & LLL & .1213 & .1002 & .3627 & .2176 \\
\hline $\begin{array}{l}\text { Scientific co-publications: International scientific co- } \\
\text { publication per million population }\end{array}$ & IntPub & .3198 & .1861 & .5582 & .2052 \\
\hline $\begin{array}{l}\text { Most-cited publications: Scientific publications among } \\
\text { the top-10\% most cited publications (\%) }\end{array}$ & CitPub & .2489 & .0773 & .5161 & .1220 \\
\hline RङD expenditure public sector as percentage of GDP & PubRD & .3229 & .1587 & .5481 & .1890 \\
\hline ReD expenditure business sector as percentage of GDP & BussRD & .3373 & .1638 & .4827 & .2214 \\
\hline $\begin{array}{l}\text { Non-Re } r \text { innovation expenditures in SMEs as percentage } \\
\text { of turnover }\end{array}$ & NonRD & .5268 & .2204 & .5323 & .1721 \\
\hline Product or process innovators in SMEs as percentage of SMEs & $\begin{array}{l}\text { Prod } \\
\text { Inno }\end{array}$ & .2535 & .1421 & .5409 & .1411 \\
\hline $\begin{array}{l}\text { Marketing or organisational innovators in SMEs as percentage } \\
\text { of SMEs }\end{array}$ & $\begin{array}{l}\text { Mark } \\
\text { Inno }\end{array}$ & .2105 & .1334 & .5218 & .1281 \\
\hline SMEs Innovating in-house as percentage of SMEs & $\begin{array}{l}\text { Inhouse } \\
\text { Inno }\end{array}$ & .2418 & .1441 & .5334 & .1548 \\
\hline $\begin{array}{l}\text { Innovative SMEs collaborating with others as percentage } \\
\text { of SMEs }\end{array}$ & $\begin{array}{l}\text { Collab } \\
\text { Inno }\end{array}$ & .2051 & .1521 & .4173 & .2484 \\
\hline Public-private co-publications per million population & $\begin{array}{l}\text { PubBuss } \\
\text { Copub }\end{array}$ & .1670 & .1502 & .3649 & .2182 \\
\hline PCT patent applications per billion regional GDP & PctPats & .1290 & .0828 & .3822 & .2259 \\
\hline Trademark applications per billion regional GDP & TradeM & .2486 & .1456 & .4023 & .2081 \\
\hline Design applications per billion regional GDP & Designs & .3846 & .2071 & .4218 & .2162 \\
\hline $\begin{array}{l}\text { Employment in medium \& high-tech manufacturing \& knowl- } \\
\text { edge-intensive services (\% of workforce) }\end{array}$ & Empl & .4525 & .23825 & .4552 & .1820 \\
\hline $\begin{array}{l}\text { Sales new-to-market and new-to-form Innovations in SMEs as } \\
\text { percentage of turnover }\end{array}$ & Sales & .3587 & .14628 & .5843 & .1615 \\
\hline \multirow{2}{*}{ B. Structural Indicators } & & \multicolumn{2}{|c|}{ CEE regions } & \multicolumn{2}{|c|}{ Non-CEE regions } \\
\hline & & \multicolumn{2}{|c|}{$\mathrm{N}=57$} & \multicolumn{2}{|c|}{$\mathrm{N}=163$} \\
\hline Definitions & Name & Mean & STD & Mean & STD \\
\hline GDP per capita: Real GDP, euro per inhabitant & GDP & 12700 & 6834.57 & 32414 & 12051.09 \\
\hline Employment in Agriculture (NACE A), \% in total employment & EmplAgri & .0828 & .0791 & .0383 & .0485 \\
\hline Employment in Industry (NACE B-F), \% in total employment & Empl Ind & .3285 & .0755 & .2212 & .0709 \\
\hline Employment in Services (NACE G-U), \% in total employment & $\begin{array}{l}\text { Empl } \\
\text { Serv }\end{array}$ & .5846 & .1027 & .7269 & .0704 \\
\hline Population density: Persons per square kilometre & Dens & 237.37 & 573.04 & 405.82 & 988.22 \\
\hline
\end{tabular}

Source: Own preparation based on European Commission (2019) and Eurostat (2020). 
Table 2.

Eingenvalues

\begin{tabular}{ccccc}
\hline Function & Eigenvalue & \% of variance & Cumulative $\%$ & Canonical correlation \\
\hline 1 & $5.201^{*}$ & 100.0 & 100.0 & .916 \\
\hline
\end{tabular}

Note:

* First 1 canonical discriminant functions were used in the analysis.

Source: Own preparation.

Table 3.

Wilks’ Lambda

\begin{tabular}{ccccc}
\hline Test of function(s) & Wilks' Lambda & Chi-square & df & Sig. \\
\hline 1 & .161 & 373.141 & 13 & .000 \\
\hline
\end{tabular}

Source: Own preparation.

Table 4.

Structure matrix

\begin{tabular}{|c|c|}
\hline \multirow{2}{*}{ Indicators } & Function \\
\hline & 1 \\
\hline CitPub & .511 \\
\hline MarkInno & .499 \\
\hline ProdInno & .409 \\
\hline InHouseInno* & .406 \\
\hline Sales & .302 \\
\hline IntPub* & .301 \\
\hline LLL & .299 \\
\hline PCTPats & .279 \\
\hline PubRD & .257 \\
\hline CollabInno & .207 \\
\hline PubBussCopub & .190 \\
\hline BussRD & .131 \\
\hline TradeM* & .083 \\
\hline Designs & .032 \\
\hline Empl & .022 \\
\hline Tert_edu* & .020 \\
\hline NonRD & .017 \\
\hline
\end{tabular}

Note:

Variables ordered by absolute size of correlation within function.

* This variable not used in the analysis.

Source: Own preparation. 
Table 5.

Functions at Group Centroids

\begin{tabular}{|c|c|}
\hline \multirow{2}{*}{ G } & Function \\
\hline & 1 \\
\hline CEE & -3.755 \\
\hline Non-CEE & 1.372 \\
\hline
\end{tabular}

Note:

Unstandardized canonical discriminant functions evaluated at group means.

Source: Own preparation.

Table 6.

Classification Results*

\begin{tabular}{rccccr}
\hline & & G & \multicolumn{2}{c}{ Predicted Group Membership } & \multicolumn{2}{c}{ Total } \\
& & CEE & Non-CEE & \multicolumn{1}{c}{1} \\
\hline \multirow{3}{*}{ Original } & & CEE & 54 & 3 & 57 \\
& Count & Non-CEE & 2 & 161 & 163 \\
& & CEE & 94.7 & 5.3 & 100.0 \\
& Non-CEE & 1.2 & 98.8 & 100.0 \\
\hline
\end{tabular}

* $97.7 \%$ of original grouped cases correctly classified.

Source: Own preparation.

Table 7.

Innovation performance and structural conditions

\begin{tabular}{lcccccc}
\hline $\begin{array}{l}\text { Pearson correlations/ } \\
\text { (Sig. 2-tailed) }\end{array}$ & $\begin{array}{c}\text { Discriminant } \\
\text { function }\end{array}$ & GDP & DENS & Empl Agri & Empl Ind & Empl Serv \\
\hline Discriminant & 1 & $.705^{* *}$ & $.149^{*}$ & $-.371^{* *}$ & $-.518^{* *}$ & $.617^{* *}$ \\
function & & .000 & .030 & .000 & .000 & .000 \\
GDP per capita & $.705^{* *}$ & 1 & $.334^{* *}$ & $-.685^{* *}$ & $-.326^{* *}$ & $.630^{* *}$ \\
& .000 & & .000 & .000 & .000 & .000 \\
Population density & $.149^{*}$ & $.334^{* *}$ & 1 & $-.523^{* *}$ & $-.405^{* *}$ & $.461^{* *}$ \\
& .030 & .000 & & .000 & .000 & .000 \\
Employment & $-.371^{* *}$ & $-.685^{* *}$ & $-.523^{* *}$ & 1 & $.152^{*}$ & $-.662^{* *}$ \\
in Agriculture & .000 & .000 & .000 & & .024 & .000 \\
Employment & $-.518^{* *}$ & $-.326^{* *}$ & $-.405^{* *}$ & $.152^{*}$ & 1 & $-.760^{* *}$ \\
in Industry & .000 & .000 & .000 & .024 & & .000 \\
Employment & $.617^{* *}$ & $.630^{* *}$ & $.461^{* *}$ & $-.662^{* *}$ & $-.760^{* *}$ & 1 \\
in Services & .000 & .000 & .000 & .000 & .000 & 1 \\
\hline
\end{tabular}

Source: Own preparation. 


\section{Chart 1.}

Economic performance and regional innovation in CEE vs Non-CEE regions

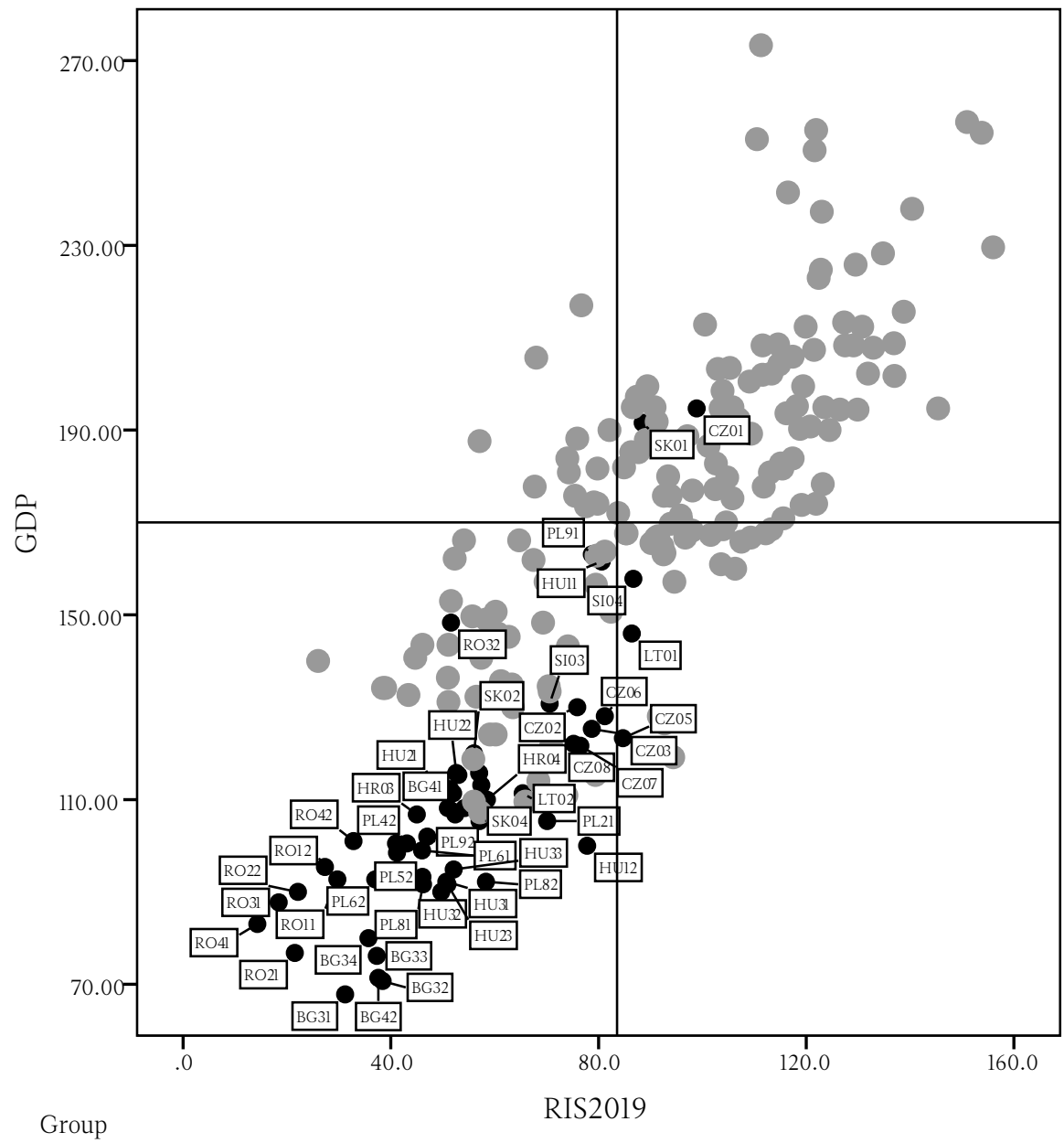

- CEE

Non-CEE

Source: Own preparation based on European Commission (2019) and Eurostat (2020). 
